\begin{tabular}{c} 
Volume and Issues Obtainable at Center for Sustainability Research and Consultancy \\
Sustainable Business and Society in Emerging Economies \\
ISSN: $2708-2172$ \& (E): $2708-2504$ \\
Volume 3: Issue 12021 \\
CSRᄃ \\
Journal homepage: $\underline{\text { www.publishing.globalcsrc.org/sbsee }}$ \\
\hline
\end{tabular}

\title{
Organizational Learning and Innovation and its Impact on Professional Accountants Organizational Citizenship Behavior: Evidence from Pakistan
}

Muhammad Aamir, Hailey College of Commerce, University of the Punjab, Lahore, Pakistan *Ahmad Usman Shahid, Management Sciences Department, COMSATS University Islamabad, Vehari, Pakistan

Hafiza Sobia Tufail, Management Sciences Department, COMSATS University Islamabad, Vehari, Pakistan

Jawad Shahid, Institute of Quality and Technology Management, University of the Punjab, Lahore, Pakistan

*Corresponding author's email address: ahmadusman1990@ ciitvehari.edu.pk

\begin{tabular}{l}
\hline ARTICLE DETAILS \\
\hline History \\
Revised format: Feb 2021 \\
Available Online: Mar 2021
\end{tabular}

Keywords

Organizational Innovation,

Learning, Citizenship

Behavior, and Accountants.

JEL Classification

M31, L66, and F23

\section{ABSTRACT}

Purpose: This study develops a theoretical model that explores the effect of organizational learning on the organizational citizenship behavior of professional accountants in Pakistan. Additionally, the model also explores the mediating role of organizational innovation between this relationship.

Design/Methodology/Approach: Data were gathered from professional accountants at small accounting firms in Pakistan.

Findings: The findings prove that organizational learning positively influences the citizenship behavior of accountants. Additionally, the findings also report the mediating role of organizational innovation between organizational learning and accountants' organizational citizenship behavior.

Implications/Originality/Value: The findings of this paper may have both practical and theoretical implications for researchers, domestic and international companies.

\section{OPEN ACCESS}

(C) 2021 The authors, under a Creative Commons Attribution-

NonCommercial- 4.0

Recommended citation: Aamir, M., Shahid, A. U., Tufail, H. S. and Shahid, J. (2021). Organizational Learning and Innovation and its Impact on Professional Accountants Organizational Citizenship Behavior: Evidence from Pakistan. Journal of Sustainable Business and Society in Emerging Economies, 3 (1), 13-24.

\section{Introduction}

This paper develops a theoretical model that explores the effect of organizational learning (OL) on organizational citizenship behavior (OCB) of professional accountants in Pakistan. Additionally, the current study also explores the mediating role of organizational innovation (OI) between OL and accountants' OCB. More recently, OL has gained global recognition among firms and academicians as well (Benson, 1997; Leslie, Aring, \& Brand, 1998; Sloman \& Webster, 2005; Wahab, Saad, \& Selamat, 2014; Park, \& Kim, 2018; Hutomo, \& Pudjiarti, 2021). This move reflects the significance of OL as an antecedent to gain a competitive advantage over competitors in complex economic settings (Senge, 
1990; Illeris, 2003; Sambrook, 2005; Wahab, Saad, \& Selamat, 2014). To achieve this objective, organizations are more likely to depend on individuals who are enthusiastic to participate in the growth of the organization, irrespective of formal job responsibilities (Somech \& Drach- Zahavy, 2004). Specifically, individuals' behaviors that excel formal job description are important for an organizations' success and survival and referred to as OCB (Katz \& Kahn, 1978; Brief \& Motowidlo, 1986; George \& Bettenhausen, 1990). Prior literature has clearly shown that OCBs are influenced by crucial contextual factors including organizational culture and more specifically, learning and innovation at the workplace (Eisenberg \& Fabes, 1990; Schein, 1990). Organizational culture serves as a prescriptive constellation of collective beliefs and values, and defines the way how employees think, feel and behave at the workplace (Schein, 1990). Specific elements of an organization's culture such as organizational learning and innovation may affect the potential of the organization to learn, which may influence the behaviors of employees. Importantly, OL starts after the apprehension of potential benefits of achieving desired outcomes by acquiring, sharing, and utilizing new knowledge and skills at the workplace (Huber, 1991; DiBella, Nevis, \& Gould, 1996; Alanoğlu \& Demirtaş, 2016). Additionally, prior literature proposed that OL allows businesses to build capacities that may enhance innovation, and only possible by acquiring new knowledge (Han, Kim, \& Srivastava, 1998; Hurley \& Hult, 1998; Baker \& Sinkula, 2002). Prior literature has long recognized the value of examining the importance of OL at the workplace (Benson, 1997; Leslie, Aring, \& Brand, 1998; Sloman \& Webster, 2005; Wahab, Saad, \& Selamat, 2014; Park, \& Kim, 2018). However, very limited research has been conducted to examine whether OL may improve the OCB of accountants, and how this relationship is mediated with OI. By drawing relevant psychology, sociology, and accounting literature, this study examines this relationship by using structural equation modeling and taking professional accountants as subjects.

Accountants at accounting firms located in major cities of Pakistan are selected for examination. Accounting firms are selected because accountants work in an environment in these organizations that continually alternates between heavy and light workloads (Whitmore \& Albers, 2006). These accountants are experienced corporate resources having the expertise to perform reporting duties and may help organizations in decision making (Wei, Choy, \& Chew, 2011; Salleh, Ahmad, SyedIkhsan, \& Lin, 2011). Additionally, accountants are skilled employees who rely on authentic information to provide reliable reporting of financial outcomes to various stakeholders by following the International Financial Reporting Standards (Awad \& Ghaziri, 2004; Whitmore \& Albers, 2006). Furthermore, accountants are required to provide accurate financial information which requires stable and continuous learning within organizations. While working in an organization, accountants learn unique and sharper insights from new information and revised accounting models and standards, which is beneficial for developing their skills and expertise (Wright, 2005). Importantly, OL may help in creating a work environment for accountants that broadens the focus of their performance from immediate outcomes to continuous improvement (Somech \& Drach- Zahavy, 2004). Therefore, this study examines the impact of OL on the OCB of accountants in Pakistan.

The remaining paper is planned in the following sections. The second section provides the literature review of the study, constituting the reasons for selecting organizational learning and organizational citizenship behavior, with particular reference to organizational innovation. Section three provides details for hypotheses development and section four explains the research method. Section five shows the results of the study, tracked by data analysis and discussion of results. The final section provides details about the conclusion, limitations, and implications.

\section{Literature Review}

In this modern era, OL helps in the growth and development of domestic and international firms. Additionally, organizations have to focus on their continuous learning to maintain a competitive edge over their competitors (Dealtry \& Rademakers, 2005). Prior literature defined OL as a rigorous process through which an enterprise formulates new ideas and insights from the prior experience of employees working in the organization and can affect behaviors and enhance the firms' competencies (Fiol \& 
Lyles, 1985; Senge, 1990; Huber, 1991; Slater \& Narver, 1995). Prior literature clearly shows that OL takes place when most employees identify the possible advantage of new ideas, knowledge, and skills (Huber, 1991). Furthermore, prior literature provides evidence that OL is a continuous process where employees learn the knowledge, share ideas and information with other colleagues, jointly interpret and ultimately retain the organizational memory to be used by all workers (Sinkula, 1994; Slater \& Narver, 1995; De Weerd-Nederhof, Pacitti, Gomes, \& Pearson, 2002; Alanoğlu \& Demirtaş, 2016).

OL depends on the aptitude of a firm to adapt to its environment, identify its mistakes and develop the means for its correction (Argyris, 1977). Prior literature provides evidence that OL develops a culture of creating harmonization of goals and strategic thinking among employees, which consequently improves the organizational system approach (Senge, 1993). According to organizational learning theory, OL stresses embracing new cultural values which may ultimately influence the mindset of accountants working in firms (Ellis, Caridi, Lipshitz, \& Popper, 1999; Somech \& Drach- Zahavy, 2004). Prior literature provides evidence that OL is a time-honored approach that may influence individuals' and organizational behavior of employees (Murray \& Donegan, 2003). Additionally, organizational OL improvement both at the individual and organizational level (Somech \& Drach- Zahavy, 2004). This may also lead accountants inputting additional efforts for the success of the organization by volunteering for tasks that are not officially essential to be performed (Somech \& Drach- Zahavy, 2004). With a mutual goal to promote OL, accountants work, support, and collaborate closely with colleagues which enhances their organizational citizenship behavior. Thus, OL values are more likely to foster OCB because accountants develop an organizational system that may broaden their exposure to performing beyond their formal responsibilities (Somech \& Drach- Zahavy, 2004).

OCB represents an "individual's behavior that is discretionary, not directly or explicitly recognized by the formal reward system and in the aggregate promotes the efficient and effective functioning of the organization" (Organ, 1989, p. 4). The employees, demonstrating OCB, are dedicated to their organization and focus on its growth and development, irrespective of their formal obligations and predefined duties (Wong, Mui, \& Hui, 2006). Prior literature provides evidence that subjects' OCB has the potential to improve firms' effectiveness and efficiency by contributing to resource innovativeness, adaptability, and transformation (Organ, 1997, 1989). Importantly, OCB is necessary for the organizations to accomplish all tasks and challenges (Turnley, Bolino, Lester, \& Bloodgood, 2003; Cho \& Johanson, 2008). Prior literature suggests two categories of OCB such as OCBO (organizational), behaviors that are beneficial for a firm in general, and OCBI (individual), behaviors that are advantageous for individuals, specifically (William and Anderson, 1991). Prior literature labels the OCBO dimension as compliance and OCBI as altruism (Organ \&

Konovsky, 1989; Smith, Organ, \& Near, 1983). The term, compliance, or 'consciousness' includes factors that are general and contribute to the overall objectives of a team, department, or a firm such as punctuality at work and low absenteeism (William and Anderson, 1991; Sharma \& Jain, 2014). Additionally, the term, altruism, includes factors such as supporting an overloaded colleague, helping and guiding a new colleague, and solving a problem for other colleagues (William and Anderson, 1991; Sharma \& Jain, 2014). Hence, it is suggested that professional accountants OCBs are not stereotypically comprised of official job descriptions but helps to create a social-psychological work environment in medium-tier accounting firms in Pakistan.

In today's' globalized world, besides OL, OI may also enable an organization to identify, apply, create, and renew working methodologies to improve the extra-role performance of employees, specifically, their OCB (Nonaka \& Takeuchi, 1995). Additionally, the forces of globalization have stressed the organizations around the globe to modify the techniques they used for making their workplace innovative (Naqshbandi \& Kaur, 2013). According to prior literature "Innovation is a means of changing an organization, whether as a response to changes in its internal or external environment or as a preemptive action taken to influence an environment" (Damanpour, 1991, p. 556). OI is a significant factor 
for a firms' strategy and creates a competitive edge over other firms in global markets (Damanpour, 2014; Kilic, Ulusoy, Gunday, \& Alpkan, 2015). Importantly, OI is the combination of development and execution of innovative ideas within the corporation, it may be administrative, technical and might be related to organizational innovative culture, as well (Garcia \& Calantone, 2002; Yuan \& Woodman, 2010; Azar \& Ciabuschi, 2017; Yu, 2017). Damanpour \& Evan (1984, p. 560) suggest that "administrative innovations involve organizational structure and administrative processes, they are directly related to the basic work activities of an organization and are more directly related to its management". Importantly, within the scope of this study, OI in accounting firms may require improving the processes and being innovative in the way these firms are being operated in Pakistan. Moreover, administrative innovation may serve as a new way in accounting firms to recruit accountants, allocate all resources and formulate structures, and reward management systems. Furthermore, prior literature defined technical innovation as "innovations that occur in the technical system of an organization and are directly related to the primary work activity of the organization" (Damanpour and Evan, 1984, p. 394). Prior literature clearly shows that for the development of OI within the firm, it is necessary to create an innovative culture where all its employees may work and collaborate to develop a new idea, process, or administrative system (Škerlavaj, Song, \& Lee, 2010). Given the importance of OI, this study provides sharper insights into the mediating effect of OI including three dimensions (administrative innovation, technical innovation, and innovative culture).

\section{Hypotheses Development}

This study takes its routes from organizational learning theory which focuses on the creation of knowledge, and its utilization within the organization for facing complex challenges and increasing performance of employees (Fauske \& Raybould, 2005). Additionally, this theory further suggests that organizations should develop a culture that appreciates employees' learning, and stress on organizational innovation, which may consequently improve their organization's overall performance. Furthermore, organizations invest their resources and time in developing innovative processes, and this may help them in getting a competitive advantage in the market by enhancing their employees' and enterprises' innovativeness, and their overall performance. Prior literature also shows that OL promotes different ideas and strategic thinking and consequently leads to employees' overall performance (Senge, 1993; Alanoğlu \& Demirtaş, 2016). Based on this reasoning following hypothesis is formulated:

H1: OL has a significant impact on accountants' OCBI and OCBO.

Prior literature shows that OI includes the development of new ideas and behaviors within a social system (Damanpour, 1996). Importantly, organizations that are likely to develop a culture of learning and innovation, may lead to enhancing employees' both OCBI and OCBO (GarcíaMorales, LlorensMontes, \& Verdú- Jover, 2006). Additionally, Macey and Schneider (2008) suggest that a higher level of employee engagement in organizational innovation may lead to the flexible effort of employees that, in turn, enhance their both in-role performance (OCBI) and extrarole (OCBO) performance. Given the increase globalization and complex business environment, organization need innovation for enhancing the performance of employees (Nouri, Ghorbani, \& Soltani, 2017). Additionally, studies show that OL also serve as an antecedent to enhancing OI within the businesses (Nouri et al., 2017). Based on the above reasoning, the following hypothesis is proposed:

H2: OI mediates the relationship between OL and accountants' OCBI and OCBO.

\section{Theoretical Model}

Figure 1.0 provides details about the theoretical model developed in this study. In this model, OL serves as the independent variable, OCBI and OCBO as a dependent variable, and OI including three dimensions such as administrative, technical innovation, and innovative culture as mediating variables. 


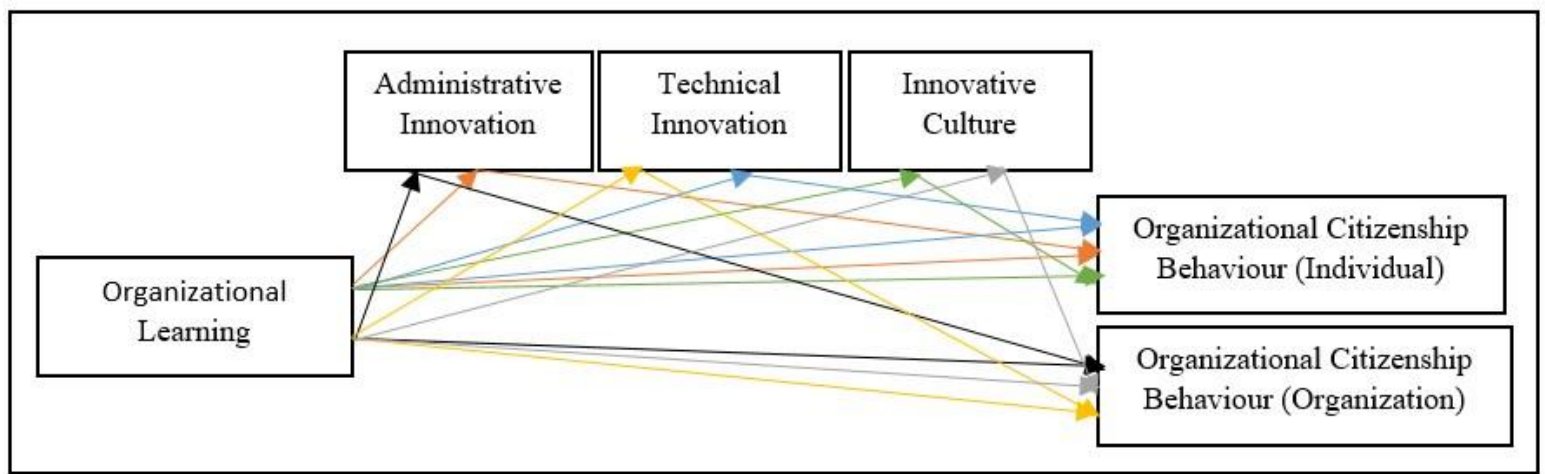

Figure 1.0. Theoretical Model

\section{Methodology}

To test the hypotheses, data were collected using a research instrument from accountants at accounting firms in Pakistan. Professional accountants for this study were randomly selected by partners of participating auditing and accounting firms, keeping in view, the provided selection criteria. Importantly, those professional accountants were selected who had relevant experience and qualifications. The subjects were informed that the provided response will be treated as unidentified. Subjects provided their demographic information required in the research instrument such as gender, qualification, age, and relevant work experience. Extensive pilot tests were conducted to ensure the appropriateness of the research instrument, using management, psychology, and accounting academicians. They were requested to examine the research instrument with a sharper focus to improve its understandability. Some minor modifications were incorporated into the research instrument, based on their valuable feedback.

The research instrument consists of two parts. Part one constitutes demographic information of respondents and part two contains a scale to capture subjects' responses for organizational learning, organizational innovation, and organizational citizenship behavior. A 4-item scale developed by AragónCorrea, García-Morales, \& Cordón-Pozo (2007) was used to capture subjects' responses for organizational learning. Furthermore, an 18-item scale developed by (Pavitt, 2005) was adapted to suit our situation, constituting dimensions such as administrative innovation, service innovation, and innovativeness or innovative culture. Moreover, a 16-item scale, developed by Lee \& Allen, (2002) was adopted to capture subjects' responses for their OCB both at individual and organizational levels.

\section{Data Analysis}

\section{Demographic Statistics}

Completed responses were received from 280 out of 310 professional accountants to whom, questionnaires were circulated, producing an overall response rate of $91 \%$. The demographic details of professional accountants are shown in table 1.0. Approximately, $91 \%$ and $9 \%$ of accountants were male and female, respectively. Of the total 280 accountants, $44.6 \%, 20.4 \%, 17.85 \%$, and $10.7 \%$, and $6.4 \%$ were of age, within the ranges of 20-29, 30-39, 40-49, and 50-59, and more than 60 years, respectively. Moreover, 64.2\%, 20.71\%, 8.9\%, 2.85\%, 1.7\% and 1.07\% accountants were junior/assistants, seniors, managers, senior managers, partners, and directors, respectively. Additionally, $21.42 \%, 35.71 \%, 25.0 \%$, $15.0 \%, 1.7 \%$, and $1.07 \%$ accountants had experience within the ranges of less than $0,1-5,6-10,11-15$, 16-20, and 21-25 years, respectively. 
Table 1.0. Demographic Statistics

\begin{tabular}{lllccc}
\hline \multicolumn{5}{c}{ Gender } \\
\hline \multicolumn{7}{c}{ Male 255 $(91 \%)$} & \multicolumn{2}{c}{ Age } & Female 25 $(9 \%)$ \\
\hline Less than 20 & $\mathbf{2 0 - 2 9}$ & $\mathbf{3 0 - 3 9}$ & $\mathbf{4 0 - 4 9}$ & More than 60 \\
$0(0 \%)$ & $125(44.6 \%)$ & $57(20.4 \%)$ & $50(17.85 \%)$ & $30(10.7 \%)$ & $18(6.4 \%)$ \\
\hline \multicolumn{7}{c}{ Current Position } \\
\hline Junior/Assistant & Senior & Manager & Senior Manager & Partner & Director \\
$182(64.2 \%)$ & $58(20.71 \%)$ & $25(8.9 \%)$ & $8(2.85 \%)$ & $5(1.7 \%)$ & $3(1.07 \%)$ \\
\hline \multicolumn{7}{c}{ Professional Experience } \\
\hline Less than 1 year & $\mathbf{1 - 5}$ years & $\mathbf{6 - 1 0}$ years & $\mathbf{1 1 - 1 5}$ years & $\mathbf{1 6 - 2 0}$ years & $\mathbf{2 1 - 2 5}$ years \\
$60(21.42 \%)$ & $100(35.71 \%)$ & $70(25.0 \%)$ & $42(15.0 \%)$ & $5(1.7 \%)$ & $3(1.07 \%)$ \\
\hline
\end{tabular}

\section{Descriptive Statistics}

Table 2.0 provides details about descriptive statistics and correlation analysis of variables such as OL, OCBI, and OCBO, three dimensions of OI including innovative culture (IC), technical innovation (TI), and administrative innovation (AI).

Table 2.0. Descriptive Statistics and Correlation Analysis

\begin{tabular}{llllllllll}
\hline & Reliability & Mean & SD & OL & OCBI & OCBO & IC & TI & AI \\
\hline OL & 0.768 & 3.75643 & 0.69 & 1 & & & & & \\
OCBI & 0.812 & 4.09999 & 0.68 & $0.544^{* *}$ & 1 & & & & \\
OCBO & 0.695 & 3.10001 & 0.59 & 0.321 & $0.443^{* *}$ & 1 & & & \\
IC & 0.711 & 3.79000 & 0.70 & $0.654^{* *}$ & $0.691^{* *}$ & $0.344^{*}$ & 1 & & \\
TI & 0.756 & 3.81000 & 0.64 & $0.692^{* *}$ & $0.531^{* *}$ & $0.456^{*}$ & $0.487^{* *}$ & 1 & \\
AI & 0.763 & 3.95621 & 0.71 & $0.564^{* *}$ & $0.623^{* *}$ & $0.399^{*}$ & $0.587^{* *}$ & $0.592^{* *}$ & 1 \\
\hline \multicolumn{8}{c}{$*$ * Significant at the $\mathrm{p}<0.05$ and $\mathrm{p}<0.01$ levels, respectively. } & &
\end{tabular}

\section{Structural Equation Modelling}

Structural equation modeling (SEM), used for data analysis, is of specific significance to this study for two reasons. First, SEM provides sharper insights into the linkage among OL, OI (administrative innovation, technical innovation, and innovative culture), and $\mathrm{OCB}$, which is consistent to examine the impact of OL on OCB, with the mediating role of OI (Byrne, 2016). Second, most of the constructs in this study are latent variables, which can only be measured by "observable items". Furthermore, the adoption of SEM is generally acceptable in social sciences because of its ability to examine the relationship "latent variables" from "observable items" (McDonald, \& Ho, 2002). By following the requirements of modeling, this paper evaluates the structural equation model in two steps (Kilne, 2015). In the first step, Confirmatory Factor Analysis (CFA) was conducted to estimate the measurement model (Kilne, 2015; Byrne, 2016). The basic purpose of CFA is to test whether the data fit a proposed measurement model, by evaluating its model fitness by key model indices including Minimum Discrepancy divided by "Degree of Freedom CMIN/DF, Comparative Fit Index (CFI), Goodness of Fit Index (GFI), Adjusted Goodness of Fit Index (AGFI), Root Mean Square Error of Estimation (RMSEA) and the P-value for a test of close fit (PCLOSE)" (Kilne, 2015; Byrne, 2016). In the second step, this paper evaluates path analysis to explain the coefficients among all variables in this study, as shown in figure 3.0.

\section{Measurement Model (Confirmatory Factor Analysis)}

Table 3.0 shows the standardized regression weights of confirmatory factor analysis. For this study, a measurement model was developed and empirically tested for conformance, regarding discriminant validity and structure of factors. Factor loading is given in table 3.0 which demonstrates that each load is statistically significant at $\mathrm{p}<0.001$, as shown in figure 2.0 . 
Table 3.0. Standardized Regression Weights

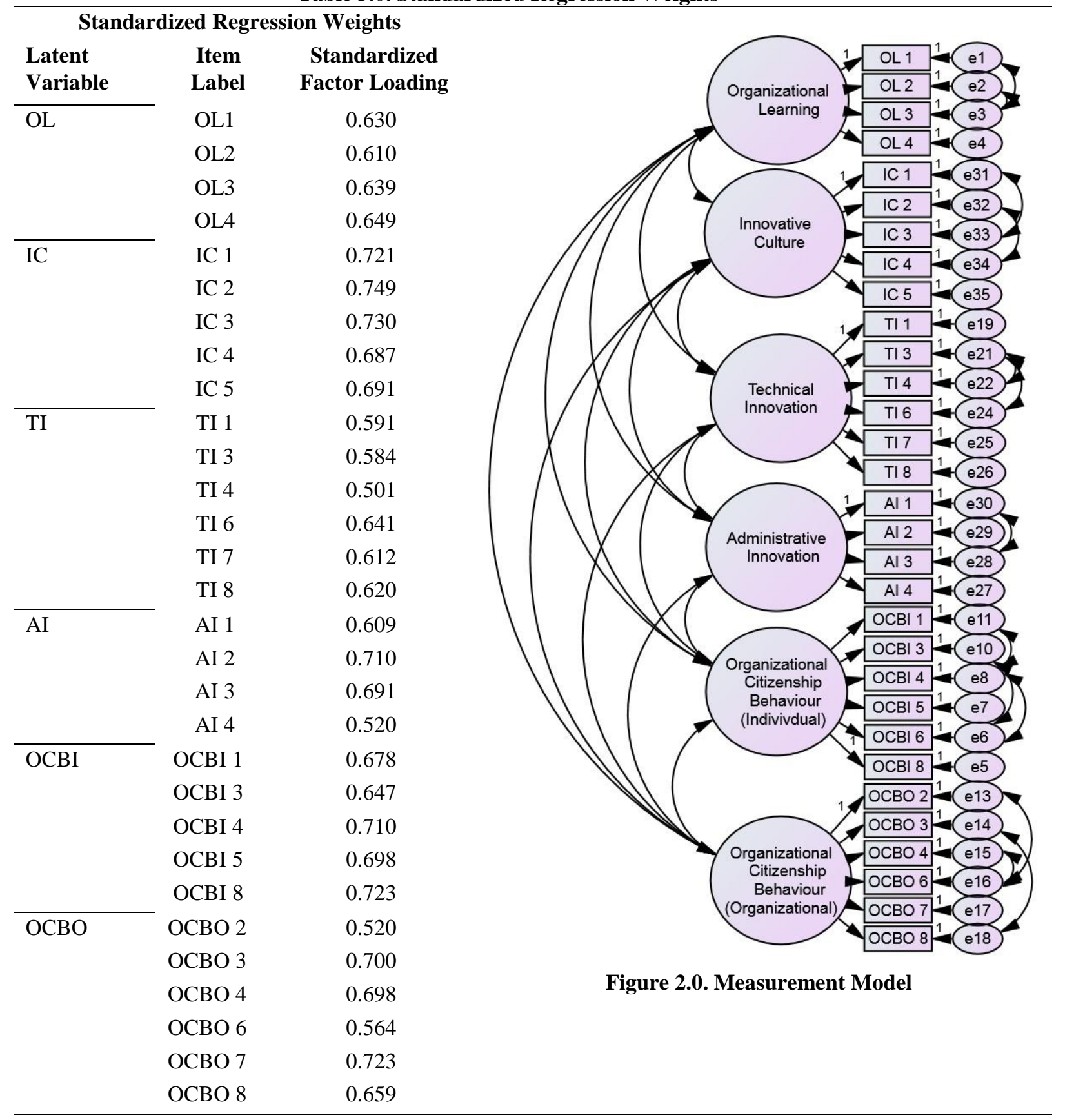

Table 4.0. shows the goodness of fit measures, as such all the values are well above the threshold indices of GFI, CFI, AGFI, PCOLSE and below the threshold indices, for RMR, CMIN/DF, and RMSEA, according to the standardized requirements (Hu, \& Bentler, 1995; Hair, Ringle, \& Sarstedt, 2011).

Table 4.0. Model Fitness Summary

\begin{tabular}{ccccccc}
\hline \multicolumn{7}{c}{ Model Fitness Summary } \\
\hline "CMIN/DF" & "RMR" & "GFI" & “AGFI" & “CFI" & "RMSEA" & "PCLOSE" \\
3.079 & 0.043 & 0.963 & 0.950 & 0.905 & 0.041 & 0.995 \\
\hline
\end{tabular}

\section{Structural Model (Path Analysis)}

The structural model demonstrates the relationship among OL, dimensions of OI including (administrative innovation, technical innovation, and innovative culture), and OCBO and OCBI. After evaluating the measurement model, a structural model was developed to explain the coefficients. 


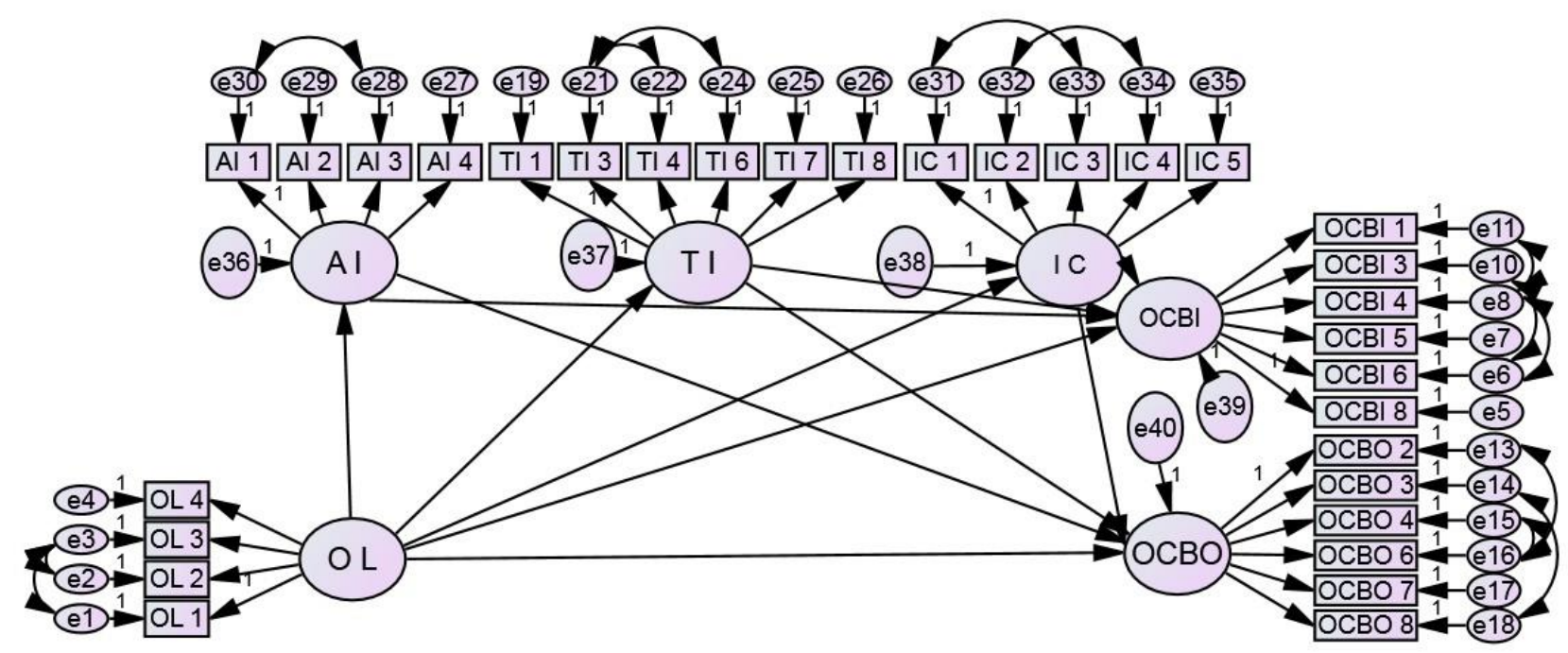

Figure 3.0. Structural Model

Consistent with the measurement model, its model fitness was also tested by using the same indices such as GFI, CFI, AGFI, PCOLSE, RMR, CMIN/DF, and RMSEA. The model shows that path coefficients are significant for all the proposed relationships among the aforementioned variables, as shown in table 5.0 .

Table 5.0. Model Fitness Summary

\begin{tabular}{ccccccc}
\hline \multicolumn{7}{c}{ Model Fitness Summary } \\
\hline "CMIN/DF" & "RMR" & "GFI" & "AGFI" & "CFI" & "RMSEA" & "PCLOSE" \\
2.63 & 0.05 & 0.94 & 0.88 & 0.97 & 0.06 & 0.005 \\
\hline
\end{tabular}

\section{Mediation Analysis}

Table 5.0 explains the results of this study, constituting all six mediation models, as shown in table 5.0. Mediation analysis was performed through bootstrapping by using AMOS. By using Bollen \& Stine (1992, p. 212) "bootstraps with 95\% bias confidence interval method", total direct and indirect effects of the proposed models were evaluated by bootstrapping for testing mediation using structural equation modeling in AMOS. In first, second and third model, administrative innovation, technical innovation, and innovative culture fully mediates between OL and OCBI. Additionally, in the fourth and fifth models, administrative innovation and technical innovation mediates the aforementioned relationship. Moreover, innovative culture also fully mediates the aforesaid relationship.

Table 5.0. Mediation Analysis

\begin{tabular}{lcccc}
\hline \multicolumn{5}{c}{ Mediation Analysis } \\
\hline Model 1 & OL-AI-OCBI & Direct Effect & Indirect Effect & Mediation Result \\
\hline Model 2 & OL-TI-OCBI & Not significant & Significant & Full mediation \\
Model 3 & OL-IC-OCBI & Not significant & Significant & Full mediation \\
Model 4 & OL-AI-OCBO & Significant & Significant & Full mediation \\
Model 5 & OL-TI-OCBO & Significant & Significant & Partial mediation \\
Model 6 & OL-IC-OCBO & Not significant & Significant & Partial mediation \\
\hline
\end{tabular}

\section{Conclusion}

This study examines the influence of OL on professional accountants' OCB, with the mediating role of 
OI. OL is an important and relevant factor for an accounting firm for its successes but with the contribution of accountants. This study provides empirical evidence that OL has a significant impact on OCBI and OCBO. Accountants working in accounting may learn new methods, administrative expertise, and technical skills, which may influence their organizational behavior to work for their benefits and overall organizational wellbeing, as well. Additionally, OI mediates this relationship between OL and OCBI and OCBO.

The findings may have several implications for accounting firms and professional accountants working there. Accounting firms should develop a culture of learning new approaches, methods, behaviors, and expertise at the workplace to tackle unforeseen circumstances and should also learn from their past experiences. Although accountants are key factors for accounting firms' growth and development, however, the question of how to improve their extra-role behaviors has not gained attention in Pakistan. Importantly, our findings provide better insights for a better understating of OL and OI for accounting firms in Pakistan and their impact on accountants' behavior. Specifically, accounting firms should promote learning, for example, by conducting, seminars, conferences, and workshops regularly, for their accountants, which may consequently fuse their research and development plans and the development of unique ideas, strategic thinking, and experimentation within the firm. Furthermore, accounting firms should also conduct regular meetings to share the knowledge, skills, expertise of one accountant with others, and develop a behavior of citizenship both at the individual and organizational level. Moreover, this study also implications for managers of accounting firms, as such they should be prepared for experimentation with various strategies, given the dynamic and complex nature of today's' workplace.

\section{References}

Alanoğlu, M., \& Demirtaş, Z. (2016). The relationships between organizational learning level, school effectiveness and organizational citizenship behavior. Journal of Education and Training Studies, 4(4), 35-44.

Aragón-Correa, J. A., García-Morales, V. J., \& Cordón-Pozo, E. (2007). Leadership and organizational learning's role on innovation and performance: Lessons from Spain. Industrial marketing management, 36(3), 349-359.

Argyris, C. (1977). Organizational learning and management information systems. Accounting, Organizations and Society, 2(2), 113-123.

Awad, E. M., \& Ghaziri., H. M. (2004). Knowledge Management.

Azar, G., \& Ciabuschi, F. (2017). Organizational innovation, technological innovation, and export performance: The effects of innovation radicalness and extensiveness. International Business Review, 26(2), 324-336.

Baker, W. E., \& Sinkula, J. M. (2002). Market orientation, learning orientation and product

innovation: delving into the organization's black box. Journal of Market-focused Management, 5(1), 5-

23.

Benson, G. (1997). Informal training takes off. Training \& Development, 51(5), 93-95.

Bies, R. J. (1989). Organizational citizenship behavior: The good soldier syndrome. In: JSTOR.

Bollen, K. A., \& Stine, R. A. (1992). Bootstrapping goodness-of-fit measures in structural equation models. Sociological Methods \& Research, 21(2), 205-229.

Brief, A. P., \& Motowidlo, S. J. (1986). Prosocial organizational behaviors. Academy of Management Review, 11(4), 710-725.

Byrne, B. M. (2016). Structural equation modeling with AMOS: Basic concepts, applications, and programming: Routledge.

Cohen, W. M., \& Levinthal, D. A. (2000). Absorptive capacity: A new perspective on learning and innovation. In Strategic Learning in a Knowledge Economy (pp. 39-67): Elsevier.

Damanpour, F. (1991). Organizational innovation: A meta-analysis of effects of determinants and moderators. Academy of Management Journal, 34(3), 555-590.

Damanpour, F. (1996). Organizational complexity and innovation: developing and testing multiple 
contingency models. Management Science, 42(5), 693-716.

Damanpour, F. (2014). Footnotes to research on management innovation. Organization Studies, 35(9), 1265-1285.

Damanpour, F., \& Evan, W. M. (1984). Organizational innovation and performance: the problem of" organizational lag". Administrative Science Quarterly, 392-409.

De Weerd-Nederhof, P. C., Pacitti, B. J., da Silva Gomes, J. F., \& Pearson, A. W. (2002). Tools for the improvement of organizational learning processes in innovation. Journal of Workplace Learning, 14(8), 320-331.

DiBella, A. J., Nevis, E. C., \& Gould, J. M. (1996). Understanding organizational learning capability. Journal of Management Studies, 33(3), 361-379.

Eisenberg, N., \& Fabes, R. A. (1990). Empathy: Conceptualization, measurement, and relation to prosocial behavior. Motivation and Emotion, 14(2), 131-149.

Ellis, S., Caridi, O., Lipshitz, R., \& Popper, M. (1999). Perceived error criticality and organizational learning: an empirical investigation. Knowledge and Process Management, 6(3), 166-175.

Fauske, J. R., \& Raybould, R. (2005). Organizational learning theory in schools. Journal of Educational Administration, 43(1), 22-40.

Fiol, C. M., \& Lyles, M. A. (1985). Organizational learning. Academy of Management Review, 10(4), 803813.

Garcia, R., \& Calantone, R. (2002). A critical look at technological innovation typology and innovativeness terminology: a literature review. Journal of Product Innovation Management: An International Publication of the Product Development \& Management Association, 19(2), 110132.

García- Morales, V. J., Llorens- Montes, F. J., \& Verdú- Jover, A. J. (2006). Antecedents and consequences of organizational innovation and organizational learning in entrepreneurship. Industrial Management \& Data Systems, 106(1), 21-24.

George, J. M., \& Bettenhausen, K. (1990). Understanding prosocial behavior, sales performance, and turnover: A group-level analysis in a service context. Journal of Applied Psychology, 75(6), 698.

Hair, J. F., Ringle, C. M., \& Sarstedt, M. (2011). PLS-SEM: Indeed a silver bullet. Journal of Marketing Theory and Practice, 19(2), 139-152.

Han, J. K., Kim, N., \& Srivastava, R. K. (1998). Market orientation and organizational performance: is innovation a missing link? The Journal of Marketing, 30-45.

Hu, L.-T., Bentler, P. M., \& Hoyle, R. H. (1995). Structural equation modeling: Concepts, issues, and applications. Evaluating Model Fit, 76-99.

Huber, G. P. (1991). Organizational learning: The contributing processes and the literatures. Organization Science, 2(1), 88-115.

Hurley, R. F., \& Hult, G. T. M. (1998). Innovation, market orientation, and organizational learning: an integration and empirical examination. The Journal of Marketing, 42-54.

Hutomo, P., \& Pudjiarti, E. (2021). Supply chain assessment of the organizational learning and market uncertainty on corporate performance of small-scale steel industry in Indonesia. Uncertain Supply Chain Management, 9(1), 39-48.

Illeris, K. (2003). Workplace learning and learning theory. Journal of Workplace Learning, $15(4)$,

167-178.

Jiménez-Jiménez, D., \& Sanz-Valle, R. (2011). Innovation, organizational learning, and performance. Journal of Business Research, 64(4), 408-417.

Katz, D., \& Kahn, R. L. (1978). The social psychology of organizations (Vol. 2): Wiley New York.

Kilic, K., Ulusoy, G., Gunday, G., \& Alpkan, L. (2015). Innovativeness, operations priorities and corporate performance: An analysis based on a taxonomy of innovativeness. Journal of Engineering and Technology Management, 35, 115-133.

Kline, R. B. (2015). Principles and practice of structural equation modeling: Guilford 
publications.

Lee, K., \& Allen, N. J. (2002). Organizational citizenship behavior and workplace deviance: The role of affect and cognitions. Journal of Applied Psychology, 87(1), 131.

Leslie, B., Aring, M. K., \& Brand, B. (1998). Informal learning: The new frontier of employee \& organizational development. Economic Development Review, 15(4), 12.

McDonald, R. P., \& Ho, M.-H. R. (2002). Principles and practice in reporting structural equation analyses. Psychological methods, 7(1), 64.

Macey, W. H., \& Schneider, B. (2008). The meaning of employee engagement. Industrial and Organizational Psychology, 1(1), 3-30.

Murray, P., \& Donegan, K. (2003). Empirical linkages between firm competencies and organisational learning. The Learning Organization, 10(1), 51-62.

Naqshbandi, D. M., \& Kaur, S. (2013). A study of organizational citizenship behaviours, organizational structures and open innovation. International Journal of Business and Social Science, 2(6), 182193.

Nonaka, I., \& Takeuchi, H. (1995). The knowledge creation company: how Japanese companies create the dynamics of innovation. In: New York: Oxford University Press.

Nouri, B. A., Ghorbani, R., \& Soltani, M. (2017). The effect of knowledge management on organizational innovation with the mediating role of organizational learning (case study: Agricultural Bank in Iran). Journal of Applied Economics and Business Research JAEBR, 7(3), 194-211.

Organ, D. W., \& Konovsky, M. (1989). Cognitive versus affective determinants of organizational citizenship behavior. Journal of Applied Psychology, 74(1), 157.

Park, S., \& Kim, E.-J. (2018). Fostering organizational learning through leadership and knowledge sharing. Journal of Knowledge Management.

Pavitt, K. (2005). Innovation processes. In The Oxford handbook of innovation.

Salleh, K., Ahmad, S. N. S., Syed-Ikhsan, S. O. S., \& Lin, B. (2011). The joint effects of organisational leadership and learning factors of professional intellects in sharing knowledge and innovation. International Journal of Innovation and Learning, 10(2), 103-122.

Sambrook, S. (2005). Factors influencing the context and process of work-related learning: Synthesizing findings from two research projects. Human Resource Development International, 8(1), 101-119. Schein, E. H. (1990). Organizational culture (Vol. 45): American Psychological Association.

Senge, P. (1990). The fifth discipline: The art and science of the learning organization. New York: Currency Doubleday.

Senge, P. M. (1993). Transforming the practice of management. Human Resource Development Quarterly, 4(1), 5-32.

Sharma, V., \& Jain, S. (2014). A scale for measuring organizational citizenship behavior in manufacturing sector. Pacific Business Review International, 6(8), 57-62.

Sinkula, J. M. (1994). Market information processing and organizational learning. The Journal of Marketing, 35-45.

Škerlavaj, M., Song, J. H., \& Lee, Y. (2010). Organizational learning culture, innovative culture and innovations in South Korean firms. Expert Systems with Applications, 37(9), 6390-6403.

Slater, S. F., \& Narver, J. C. (1994). Market orientation, customer value, and superior performance. Business oHrizons, 37(2), 22-29.

Slater, S. F., \& Narver, J. C. (1998). Customer- led and market- oriented: let's not confuse the two. Strategic Management Journal, 19(10), 1001-1006.

Sloman, M., \& Webster, L. (2005). Training to Learning: New business models dictate a different kind of workplace learning. T AND D, 59(9), 58.

Smith, C., Organ, D. W., \& Near, J. P. (1983). Organizational citizenship behavior: Its nature and antecedents. Journal of APPLIED PSYCHOLOGY, 68(4), 653.

Somech, A., \& Drach- Zahavy, A. (2004). Exploring organizational citizenship behaviour from an 
organizational perspective: The relationship between organizational learning and organizational citizenship behaviour. Journal of Occupational and Organizational Psychology, 77(3), 281-298.

Tippins, M. J., \& Sohi, R. S. (2003). IT competency and firm performance: is organizational learning a missing link? Strategic Management Journal, 24(8), 745-761.

Wahab, M. S. A., Saad, R. A. J., \& Selamat, M. H. (2014). A survey of work environment inhibitors to informal workplace learning activities amongst Malaysian accountants. Procedia-Social and Behavioral Sciences, 164, 409-414.

Wei, C. C., Choy, C. S., \& Chew, G. G. (2011). The KM processes in Malaysian SMEs: an empirical validation. Knowledge Management Research \& Practice, 9(2), 185-196.

Whitmore, B., \& Albers, J. A. (2006). Knowledge management in an accounting organization. Journal of Knowledge Management Practice, 7(4).

Williams, L. J., \& Anderson, S. E. (1991). Job satisfaction and organizational commitment as predictors of organizational citizenship and in-role behaviors. Journal of management, 17(3), 601-617.

$\mathrm{Yu}$, P. L. (2017). Innovative culture and professional skills: The use of supportive leadership and individual power distance orientation in IT industry. International Journal of Manpower, 38(2), 198-214.

Yuan, F., \& Woodman, R. W. (2010). Innovative behavior in the workplace: The role of performance and image outcome expectations. Academy of Management Journal, 53(2), 323-342. 